\title{
Assessment of Prophetic Foods Consumption among Lactating Mothers: Combining Quantitative \& Qualitative Approaches
}

Siti Munirah Abdul Basir ${ }^{1}$, Nor Azwani Mohd Shukri ${ }^{1}$, Radiah Abdul Ghani ${ }^{2}$, Muhammad Ibrahim ${ }^{1}$,Muhammad Muzaffar Ali Khan Khattak ${ }^{1}$, Muhammad Nor Omar ${ }^{3}$

${ }^{1}$ Department of Nutrition Sciences, Kulliyyah of Allied Health Sciences, International Islamic University Malaysia, Jalan Sultan Ahmad Shah, Bandar Indera Mahkota, 25200, Kuantan, Pahang, ${ }^{2}$ Department of Biomedical Sciences, Kulliyyah of Allied Health Sciences, International Islamic University Malaysia, ${ }^{3}$ Department of Biotechnology, Kulliyyah of Sciences, International Islamic University Malaysia

\begin{abstract}
Introduction: The phrase 'Prophetic food and medicine' reflects the words and actions of the Holy Prophet Muhammad (PBUH) with the bearing of disease, treatment of disease, and care of patients. Among plants mentioned in the Al-Quran, Al-Hadith and Islamic literature are dates, pomegranates, figs, olive and black cumin seeds. These plants are widely used for medicinal purposes, as functional foods and industrial products. However, there are limited studies found regarding their effect on human milk quality and quantity. Thus, this paper aims to describe the methodology to assess knowledge, attitude, and practice of prophetic foods consumption among lactating mothers in Kuantan, Pahang. Methodology: Pregnant Malay mothers aged 18 to 40 years old, at a gestational duration of $\geq 32$ weeks, are recruited. During the lactation period, their dietary intake (specifically the consumption of prophetic foods) are assessed using a quantitative method which is food frequency questionnaire. A subsample of these mothers is then interviewed using semi-structured interview method on the prophetic food consumption. Quantitative and qualitative data are analysed using SPSS and NVivo software, respectively. Result: Reports of positive effects of prophetic food consumption on lactation experience namely improving human milk production is anticipated from this study. In addition, it will provide a foundation for further exploration of the role of prophetic food consumption in the lactation process. Conclusion: This research is at the forefront to provide the data on potential practice and application of prophetic foods in positively influencing lactation experience and quality of human milk.
\end{abstract}

KEYWORDS: prophetic food, lactation, dietary assessment

\section{INTRODUCTION}

The phrase 'Prophetic food and medicine' reflects the words and actions of the Holy Prophet Muhammad (PBUH) with relation to disease, treatment of disease, and patients' care. ${ }^{1}$ This also includes His words on medical matters, medical treatment practiced by others on the Prophet, medical treatments practised by the Prophet on himself and others, medical treatments observed by the Prophet with no objections, medical procedures that the Prophet heard or knew about and did not prohibit, or medical practices which were so common that the Prophet could not have failed to know about them. ${ }^{1}$ Narrated by Abu Huraira: The Prophet said, "There is no disease that Allah has created, except that $\mathrm{He}$ also has created its treatment." The specific remedies taught by the Prophet (PBUH) are valid and useful. These, however, may not be used today without undertaking further empirical research because of

Siti Munirah Abdul Basir

Department of Nutrition Sciences,

Kulliyyah of Allied Health Sciences,

International Islamic University Malaysia,

Kuantan Campus.

Email: munirah.basir@live.iium.edu.my changes in the human and physical environments.

Among plants mentioned in the Al-Quran, Al-Hadith and Islamic literature are dates, pomegranates, figs, olives and black cumin seeds. ${ }^{2}$ These plants are widely used for medicinal purposes such as to treat common colds, diabetes, and eczema, as functional foods i.e. to improve milk production and improving memory. ${ }^{3-5}$ In addition, these plants are also utilised in industrial products such as facial cleanser, acne treatment, and supplementary products.

The World Health Organization (WHO) and United Nations Children's Fund (UNICEF) strongly advocate exclusive breastfeeding for the first six months after birth as the optimal way of feeding infants. This is based on a review of evidence which demonstrated its benefits on child health, nutritional, immunologic, developmental, psychological, social, economic, and environmental status, as well as, its positive implications on maternal wellbeing. ${ }^{6}$ In addition, WHO is now targeting to increase the rate of exclusive breastfeeding in the first six months up to at least $50 \%$ by the year $2025 .^{7}$ The Malaysian government has consequently adopted this recommendation which encourages mothers to practice breastfeeding from birth until six months and continue to breastfeed 
for two years in its Malaysian Dietary Guidelines (MDG) ${ }^{8,9}$ The recommendation has been strengthened as Key Message 1 in the recent MDG 2013.

However, breastfeeding is not without its challenges. There are a number of reasons related to the inability to continue with breastfeeding among some new mothers. Among the common causes of early termination of breastfeeding is the perception of insufficient milk production by the mother and/or insufficient milk intake by the baby. ${ }^{10,11}$ In addition, lack of information and support has been reported to influence breastfeeding cessation. ${ }^{12,13}$ Other reasons found in the literature include concern about infant's nutritional status, difficulties related to lactation and milk-pumping effort, - baby's inability to suckle, fear of painful breasts and low breastfeeding self-efficacy among mothers. ${ }^{14-17}$

In relation to this, there are very limited studies found on prophetic foods consumption and their potential role in breastfeeding. Current review found only one study that showed a positive relationship between consumption of palm dates and quantity of human milk. ${ }^{3}$ In addition, there are many claims of the benefits of prophetic foods (including for breastfeeding) which have yet to be proven scientifically. These gaps warrant investigation. Thus, the main aim of this paper is to describe the methodology used in the current study to assess the knowledge, attitude, and practice of prophetic foods consumption among lactating mothers in Kuantan, Pahang.

\section{METHODOLOGY}

\section{Setting and participants}

Study participants are being recruited from areas around Kuantan, Pahang. The recruitment is done by online advertisement and direct recruitment at a few health care settings. A total of 152 mothers are targeted to be included in this study. The study size is determined by using a single mean formula as stated below:

$$
\begin{aligned}
\mathrm{n}= & {\left[\mathrm{Z}_{\mathrm{a} / 2} \times \underline{\sigma}\right]^{2} } \\
& \Delta \\
& =[1.96 \times 0.3 / 0.05]^{2} \\
= & 138.3+10 \% \text { attrition } \\
\approx & 152 \\
& { }^{2} \mathrm{Z}_{\alpha / 2}: 95 \% \text { confidence interval } \\
& \sigma: \text { standard deviation from literature } \\
& \Delta: \text { precision }
\end{aligned}
$$

\section{Inclusion Criteria}

These include pregnant women aged between 18 to 40 years old, with singleton pregnancy at week 32 and onwards, are motivated to exclusively breastfeed, and deliver a full-term baby at least at 37 weeks of gestation; or women of the mentioned age, who are exclusively breastfeeding a baby aged six months or younger.

\section{Exclusion Criteria}

These include pregnant women: with the diagnosis of any pre-existing chronic diseases such as diabetes mellitus and cardiovascular diseases, with any pregnancy complications such as hyperemesis gravidarum, pregnancy-induced hypertension, and gestational diabetes; who practice tandem nursing; and who deliver a preterm baby (less than 37 weeks of gestation).

During the study, data are obtained only for as long as the mothers exclusively breastfeed their babies during the six-month postnatal period. Each procedure involved in this study is clearly explained before obtaining the participants' verbal and written consents.Figure 1 illustrates the general methodology of the study.

\section{Variables}

Data on socio-demographic characteristics, obstetric history, smoking status, physical activity, and any dietary intake of multivitamins and/ or galactagogue supplements, during the study, are collected using an interviewer - administered questionnaire.Compared to a self-administered questionnaire, this method allows for questions clarification, ensures completion of the questionnaire, obtains higher response rate and has higher control of the environment. ${ }^{18}$ In addition, breastfeeding record such as frequency of breastfeeding, the duration of each breastfeeding, and the number of wet diapers of the babies, are also collected.

\section{Quantitative Assessment}

The quantitative assessment of the prophetic food consumption is carried out by using a food frequency questionnaire (FFQ). This contains a list of foods and beverages, with sections to report the frequency and quantity of foods/ beverages consumed over a specified period. ${ }^{19}$ The FFQ method represents an individual's 'habitual' intake.

\section{Development of questionnaire}

To date, there is no FFQ on prophetic foods available in the literature. Hence, the FFQ used in this study is newly developed through several steps. Firstly, a list of foods mentioned in the Al-Quran, Al-Hadith and Islamic literature is obtained through literature review. Eight foods which are commonly recognized and consumed by Malaysians are included in the FFQ. These include palm date, raisin, black seed (Habbatus Sauda), honey, pomegranate, milk, fig, and olive. For each food, the amount taken per day is recorded. Other than that, the frequency of consumption is assessed on a daily and weekly basis. This is to determine the nutrients and total energy contribution from these foods in the daily dietary intake of the participants. In addition, the reasons for consumption of the foods are also noted. This quantitative assessment is carried out on the $30^{\text {th }}$ and $90^{\text {th }}$, days of postpartum. 
Before commencement of the actual study, a pilot study has been conducted to assess the acceptability of the FFQ. A total of 10 participants were randomly chosen to participate in the study. Based on the pilot study, a new food (fenugreek) is added to the list. Other than that, the item 'amount taken per day' is rephrased as 'amount taken per eating session'.

\section{Qualitative assessment}

A subsample of mothers who has completed the quantitative assessment as explained earlier are then interviewed using semi-structured interview method. The objective of this is to further explore the consumption of prophetic foods during the lactation period. A qualitative study is chosen because it would assist in understanding a person's interpretation and experience on a subject matter. In this case, the intention is to investigate the mothers' knowledge, attitude and practice on prophetic foods consumption during the exclusive breastfeeding period. Knowledge can be defined as the mothers' understanding about prophetic foods or prophetic diet. Attitude refers to their perception about prophetic foods consumption such as its perceived benefits or harm. Practice, on the other hand, depicts the way the mothers demonstrate their knowledge and attitude on prophetic foods through their actions.

A semi-structured interview is a type of in-depth interview which may consist of open- and closeended questions. It allows researchers to develop a better understanding on the topic of interest. ${ }^{20}$ Study participants are interviewed individually. Generally, the questions asked during the interview revolve around these topics:

-Understanding about prophetic foods

-Giving examples of prophetic foods

-Consumption of any prophetic foods during breastfeeding period

-The reason for consuming the prophetic food(s), if they do

The number of included participants in this qualitative assessment is determined by the saturation of information obtained. The interview is recorded using a voice recorder and is transcribed prior to analysis.

\section{Statistical and qualitative analyses}

The nutritional intake from prophetic foods is estimated based on the Nutrient Composition of Malaysian Foods database and U.S. Department of Agriculture (USDA) Foods database. Association between maternal intake of prophetic foods and nutrient contents of breast milk is assessed by using Pearson correlation. This is performed using IBM SPSS Version 20.0 with confidence interval level set at $95 \%$.

For the qualitative analysis, NVivo analysis software is used. All information and answers obtained from the interview are recorded in this software. It assists in organizing and analysing the qualitative information obtained from the interview with the participants. The content of the interviews will be analysed thematically into knowledge, attitude and practice codes. Once a pattern is identified, the recruitment for the interview shall be ended.

\section{Ethical Approval and Informed Consents}

This study has been approved by the International Islamic University Malaysia Research Ethics Committee (IREC). Signed informed consent is prepared in both English and Malay. Verbal and written consents are obtained in the presence of a witness after each procedure involved in this study is clearly explained to the participants.

\section{RESULT}

Reports of the positive experience of prophetic food consumption on lactation including improvement of human milk production are anticipated from this study. The researchers are hoping to learn about mothers' individual knowledge and perception of prophetic foods consumption and its role during the lactation period. In addition, the mothers' attitude regarding prophetic food consumption during lactation will be analysed. We may also see prophetic foods consumption being practiced among lactating mothers from the FFQ. Other than that, this study will provide a foundation for further exploration of the role of prophetic food consumption in the lactation process.

\section{DISCUSSION}

The objective of this study is to analyse the knowledge, attitude, and practice of prophetic foods consumption during the lactation period. In order to achieve this, FFQ and qualitative interviewing are included as our methods of study.

FFQ is relatively an inexpensive research tool used for a dietary intake assessment. It can be completed quickly and is able to assess current and past diet. Also, it may be used to compare between those with high and low intakes as it allows ranking of individual's food or nutrient intake. ${ }^{21}$ Qualitative interviewing, on the other hand, helps to examine issues in detail and in depth. It may also reveal the subtlety and complexity of research subject which is often missed by quantitative inquiry. ${ }^{22}$ According to Onwuegbuzie and Leech (2005), combining both quantitative and qualitative research methodologies has their advantages. ${ }^{23}$ For instance, quantitative data would help to generalize the findings from qualitative assessment. Other than that, by having both methodologies, researchers would be able to combine the macro and micro levels of a research issue. The combination of qualitative and quantitative methodologies would also be useful in developing conceptual frameworks, validating quantitative findings by referring to findings from the qualitative study, and constructing indices from 
qualitative data that can be used to analyse quantitative data. ${ }^{24}$

In this study, the researchers are looking at the topic of prophetic food consumption among lactating mothers which has never been explored previously. By applying both quantitative and qualitative approaches, this shall ensure that information are collected as extensively and accurately as possible, and thus would lead to an improved understanding of this topic. The FFQ shall help us determine the quantitative details of prophetic foods consumption among the lactating mothers, whereas the interviewing shall provide us with the qualitative insights, such as their reasons for and opinions of it.

\section{CONCLUSION}

Since breastfeeding would confer its benefits until beyond childhood, appropriate action can be taken and intervention can be planned to optimize its effectiveness. This research is at the forefront to provide exploratory information on the potential practice and application of prophetic foods to positively influence lactation experience and quality of human milk. Thus, a combination of quantitative as well as qualitative assessments is the appropriate method to ensure the credibility of the information obtained.

\section{ACKNOWLEDGMENT}

This study is funded by Research Initiative Grants of International Islamic University Malaysia (RIGS)

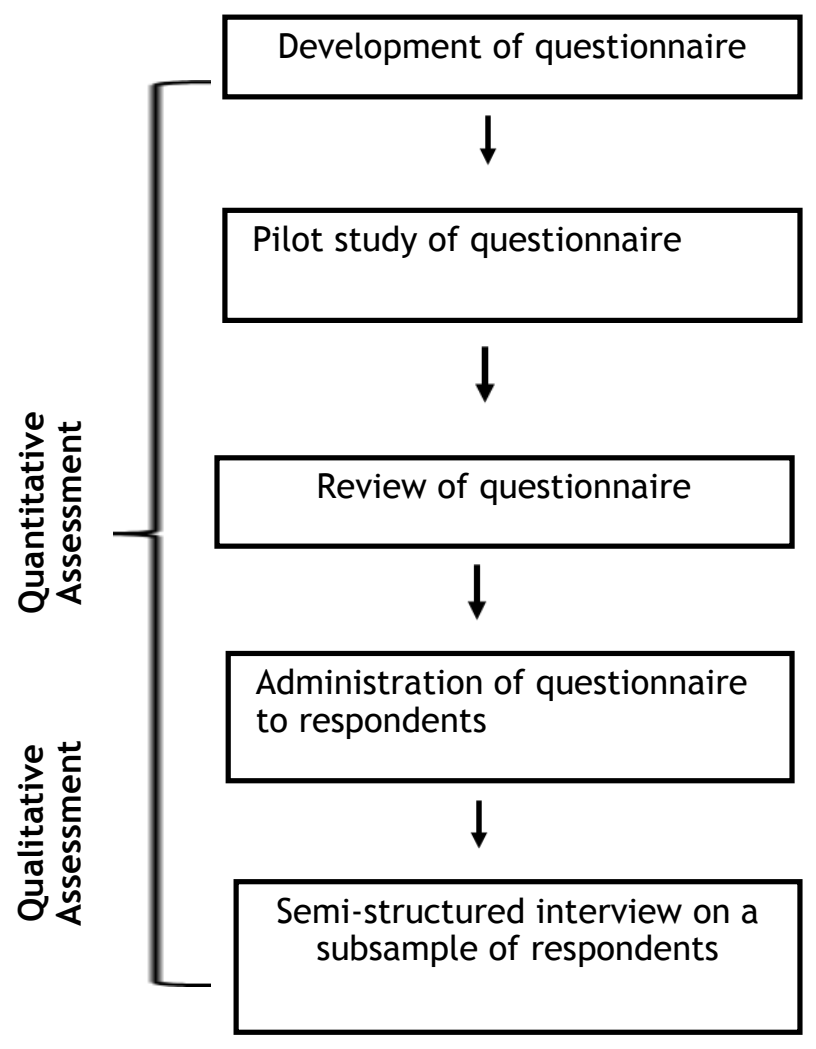

Figure 1: General methodology of the study

\section{REFERENCES}

1. Omar Hassan Kasule. Tibbn Al-Nabawi. Scibd. Available at:

https: / /www.scribd.com/document/58443210 /TIBBN-AL-NABAWI (2007). Accessed 20 April 2016

2. Mushtaq A, Mir A. K, Sarfaraz K.M., Muhammad, Z., Muhammad A.K., Tamoor, H. and Shazia. S. Useful medicinal flora enlisted in Holy Quran and Al-Hadith. AmericanEurasian J. Agric. \& Environ. Sci. 2009; 5: 126140

3. Sakka, A.E., Salama, M., and Salama, K. The Effect of Fenugreek Herbal Tea and Palm Dates on Breast Milk Production and Infant Weight. Journal of Pediatric Sciences 2014; 6: e202

4. Sheikh B.Y. The role of prophetic medicine in the management of diabetes mellitus: A review of literature. Journal of Taibah University Medical Sciences [online] 2016; available at: http://dx.doi.org/10.1016/j.jtumed.2015.12.0 02. Accessed 18 April 2016

5. Ramadhan, M. The Nutritional Value, Functional Properties and Nutraceutical Applications of Black Cumin (Nigella sativa L.): An Overview. International Journal of Food Science and Technology 2007; 42: 1208-1218. doi: 10.1111/j.1365-2621.2006.01417.x

6. Kramer, M.S. and Kakuma, R. The optimal duration of exclusive breastfeeding: a systematic review. World Health Organization 2001. Available at:

http://www.who.int/nutrition/topics/optimal _duration_of_exc_bfeeding_review_eng.pdf. Accessed 15 April 2016

7. World Health Organization (WHO): Comprehensive Implementation Plan on Maternal, Infant and Young Child Nutrition. World Health Organization Publication [online] 2014. Available at:

http://www. who.int/nutrition/publications/Cl P_document/en/. Accessed 25 April 2016

8. National Coordinating Committee on Food and Nutrition (NCCFN): Malaysian Dietary Guidelines for Children and Adolescents - Summary. Ministry of Health Malaysia [online] 2013. Available at: http://www.moh.gov.my/images/gallery/Gari spanduan/MDG\%20Children\%20and\%20Adolesce nts\%20Summary.pdf. Accessed 25 April 2016

9. National Coordinating Committee on Food and Nutrition (NCCFN). Malaysian Dietary Guidelines - Key Message 12. Ministry of Health Malaysia [online]. Available at: http://www.moh.gov.my/english.php/pages/v iew/536. Accessed 25 April 2016

10. Spencer, J.: Common Problems of Breastfeeding and Weaning. In: UpToDate [online]. Available at: http: / /www. uptodate.com/contents/commonproblems-of-breastfeeding-and-weaning. Accessed 29 March 2016

11. Wang, W., Lau, Y., Chow. A. and Chan, K.S. Breast-feeding intention, initiation and 
duration among Hong Kong Chinese women: A prospective longitudinal study. Midwifery 2014; 30: $678-687$

12. Oakley, L.L., Henderson, J., Redshaw, M. \& Quigley, M.A. The role of support and other factors in early breastfeeding cessation: an analysis data from a maternity survey in England. BMC Pregnancy \& Childbirth 2014; 18: 88

13. Agunbiade, O.M. \& Ogunleye, O.V. Constraints to exclusive breastfeeding practice among breastfeeding mothers in Southwest Nigeria: implications for scaling up. International Breastfeeding Journal 2012; 7:5

14. Brand, E., Kothari, C. \& Stark, M.A. 2011. Factors related to breastfeeding discontinuation between hospital discharge and 2 weeks postpartum. The Journal of Perinatal Education, 2011; 20: 36-44. doi: 10.189/10581234.20.2.36

15. Odom, E.C., Li, R., Scanlon, K.S., Perrine, C.G. \& Grummer-Strawn, L. 2013. Reasons for earlier than desired cessation of breastfeeding. Pediatrics, 2013; 131: e726-e732. doi: 10.1542/peds.2012-1295

16. Küçükoğlu, S. \& Gökçeoğlu, E. 2015. The relationship between insufficient milk perception and breastfeeding self-efficacy among Turkish mothers. Global Health Promotion 2015; 1-9. doi: $10.1177 / 1757975916635080$

17. Brown. Q.R.L., Dodds, L., Legge, A., Bryanton, J. \& Semenic S. 2014. Factors influencing the reasons why mothers stop breastfeeding. Canadian Journal of Public Health 2014 105: e179-e185.

18. World Health Organization (WHO). 2008. Questionnaire design. Foodborne disease outbreaks: Guidelines for investigation and control [online]. Available at: http: / / www. who.int/foodsafety/publications/f oodborne_disease/Annex_4.pdf . Accessed 5 May 2016

19. University of Colorado Danver: Food Frequency Questionnaires [online]. Available at: http://www.ucdenver.edu/research/CCTSI/pro gramsservices/ctrc/Nutrition/Documents/Food_Freq uency_Questionnaires.pdf . Accessed 5 May 2016

20. Cohen, D. and Crabtree, B.: Qualitative Research Guidelines Project [online]. Robert Wood Johnson Foundation 2006. Available at: http: / /www.qualres.org/HomeSemi-3629.html. Accessed on 14 September 2016.

21. Australian Child \& Adolescent Obesity Research Network: Dietary intake assessment - Frequent Food Questionnaire. The University of Sydney [online]. Available at: http://www.acaorn.org.au/streams/nutrition/ assessment-methods/ffq.php. Accessed 10 September 2016.

22. Anderson, C.: Presenting and evaluating qualitative research [online]. Available at: http://www.medscape.com/viewarticle/73116
5_3. Accessed on 10 September 2016.

23. Onwuegbuzie, A.J. and Leech, N.L. 2005. On becoming a pragmatic researcher: the importance of combining quantitative and qualitative research methodologies. International Journal of Research Methodology 2005; 8, 375-387. doi: $10.1080 / 13645570500402447$.

24. Madey, D. L. Some benefits of integrating qualitative and quantitative methods in program evaluation, with some illustrations. Educational Evaluation and Policy Analysis 1982; 4: 223-236. 